\title{
Água, Tecnologia e Desenvolvimento: o Caso do Programa Água Doce no Semiárido Paraibano ${ }^{11}$
}

\author{
Water, Technology and Development: the Case of the Governmental Program "Água \\ Doce" in the Semi-Arid Region of Paraiba
}

\author{
Andrea Carla de Azevêdo ${ }^{12}$ \\ Cidoval Morais de Sousa ${ }^{13}$ \\ Rebeca Casemiro ${ }^{14}$ \\ Robert Motta ${ }^{15}$
}

\begin{abstract}
RESUMO
O objetivo desta investigação foi analisar as políticas públicas de enfrentamento da escassez hídrica no Nordeste no contexto da retomada dos debates sobre o desenvolvimento regional/local. A pesquisa concentrou-se, de modo específico, no Programa Água Doce e seus impactos em comunidades paraibanas. Tomou-se como parâmetro de análise, dentre outras questões, a natureza, o processo de elaboração das políticas e a participação dos diferentes atores nelas envolvidos; os resultados de sua implantação; e a avaliação de tais políticas, considerando, fortemente, o viés das comunidades beneficiadas. Trata-se de um estudo de natureza qualitativa, com a utilização de diferentes procedimentos complementares: visitas de aproximação, observação, entrevistas abertas, conversas informais, consulta a documentos. Como resultado, observaram-se fragilidades técnicas, participação incipiente das comunidades e o alcance social se mostra pequeno diante da problemática da escassez de água para o consumo humano na região do Semiárido paraibano.
\end{abstract}

Palavras-chave: Políticas públicas. Desenvolvimento regional. Produção tecnocientífica. Programa Água Doce.

\begin{abstract}
The aim of this research was to analyze public policies meant to face water shortages in Brazilian Northeast within a context in which the debates about regional/local development are resumed. Apart from that, it tackles different policies historically and critically, focusing on Program Água Doce and its impacts on communities in the State of Paraiba. Their analysis took into account, among other things, the following aspects: nature; process of elaboration; different actors involved; results, and assessment, especially regarding the benefits brought to the assisted communities. It is a qualitative study which uses different procedures: visits, observation, open interviews, informal talks, and analysis of documents. Some of its findings point out to technical fragilities, low local-people participation, and limited social results if access to drinking water is taken into account.
\end{abstract}

Keywords: Public policies. Regional development. Techno scientific production. Desalination. Program Água Doce.

${ }^{11}$ Trabalho apresentado no dia 16 de outubro de 2013, no Grupo de Trabalho 15 - Políticas Públicas e Desenvolvimento Local: interveniências e interações entre tecnologia, sociedade e democracia.

${ }^{12}$ Doutoranda em Planejamento Urbano e Regional (IPPUR/UFRJ), Mestra em Desenvolvimento Regional pela Universidade Estadual da Paraíba (UEPB); Pesquisadora do Núcleo de Tecnologias Estratégicas em Saúde (NUTES) e Jornalista. E-mail: andreaazevedo_cg@hotmail.com

${ }^{13}$ Doutor em Geociências (UNICAMP). Professor/Pesquisador dos Programas de Pós-Graduação em Desenvolvimento Regional e Ensino de Ciências (UEPB). Colaborador do PPGCTS (UFSCAR). Diretor da Editora Universitária EDUEPB. E-mail: cidoval@gmail.com

${ }^{14}$ Jornalista e Mestra em Desenvolvimento Regional pela Universidade Estadual da Paraíba (UEPB). Email: rebecacasemiro@gmail.com

${ }_{15}$ Doutor (Ph. D.) em Antropologia pela Universidade de Columbia na cidade de Nova lorque (E. U. A.), professor-titular de Antropologia da Universidade Federal de Pernambuco e pesquisador 1-B do CNPq. Email:rmcmotta@uol.com.br 


\section{INTRODUCÃO}

Semiárido brasileiro tem apenas 3\% da água doce do País, mas abriga uma população de 22.598 .318 milhões de pessoas, o que significa quase $12 \%$ da população nacional. Desse total, mais de 40\% vivem na zona rural. Duas características históricas marcam a região: secas periódicas prolongadas, que ocorrem aproximadamente a cada dez anos, e a escassez anual de água durante o período de estiagem (OLIVEIRA, 2009; BLANK; HOMRICK; ASSIS, 2008).

A Organização Mundial de Saúde (OMS), 2001, destaca que todas as pessoas, em quaisquer estágios de desenvolvimento e condições socioeconômicas, têm direito a um suprimento adequado de água. Por isso, o fenômeno se apresenta como desafio às políticas que visam ao desenvolvimento local sustentável.

Em primeiro lugar, porque, no caso do Semiárido brasileiro, as secas carregam, historicamente, uma marca política negativa. Seu enfrentamento sempre se pautou por políticas paliativas, assistencialistas e eleitoreiras, que, longe de resolverem o problema da escassez hídrica, asseguraram a manutenção histórica de grupos oligárquicos no poder. E, em segundo, porque, também historicamente, as soluções técnicas de combate às secas apresentadas, como a construção de barragens, açudes, poços artesianos, cisternas e implantação de dessalinizadores, concentravam mais do que distribuíam a água - neste trabalho, compreendida como bem comum, patrimônio da humanidade, não privatizável.

A busca de soluções tecnológicas para o fornecimento de água aos habitantes do Semiárido brasileiro, especialmente para aqueles que vivem nas localidades rurais difusas, deve oferecer, de um lado, garantias de sustentabilidade, de forma que as atividades econômicas e sociais desenvolvidas tenham continuação e dinâmicas independentes da existência ou não de um evento de seca e, de outro, o fim das privações que comprometem a experiência das liberdades instrumentais, sem as quais não há desenvolvimento nos termos definidos por Sen (2000), apoiados neste trabalho.

Para Sen (2000), a expansão das liberdades (oportunidades econômicas, liberdades políticas, serviços sociais, garantias de transparências, segurança protetora) é importante para o desenvolvimento por duas ordens de razão: a avaliação (a apreciação do progresso tem que ser feita em termos do alargamento 
da liberdade das pessoas) e a eficácia (a qualidade do desenvolvimento depende da ação livre dos indivíduos). O que as pessoas podem efetivamente realizar depende, assim, do conjunto das liberdades e condições de que dispuserem para viver com qualidade. $\mathrm{O}$ acesso igualitário ao bem comum água é uma dessas condições.

Este trabalho tem por tema as políticas públicas de acesso à água apropriada ao consumo humano por meio do aproveitamento sustentável de águas subterrâneas. Duas perguntas nortearam a pesquisa: em que medida as políticas públicas - de acesso permanente à água potável nas regiões do Semiárido, particularmente, o paraibano - têm contribuído para a superação das dificuldades decorrentes, não só da escassez d'água nessa região, mas, sobretudo, pelo elevado teor de salinidade das águas dos poços do Semiárido? Qual o impacto social e econômico produzido por esses programas, especialmente pelo Programa Água Doce, com a instalação dos dessalinizadores?

Assim, o objetivo geral deste estudo foi investigar as políticas públicas de enfrentamento da escassez hídrica no Nordeste, com ênfase particular no Programa Água Doce (PAD), em comunidades rurais da Paraíba. Buscamos, de modo específico, realizar avaliação do PAD, considerando questões como processos de implantação, funcionamento e impactos do programa na vida das comunidades beneficiadas.

Partimos do pressuposto de que o acesso à água de qualidade e em quantidade suficiente gera transformações profundas na vida das pessoas: diminui a incidência de doenças, reorganiza as relações familiares, permite a diversificação da produção (garantindo a segurança alimentar), e rompe com a dependência política dos carros-pipa e de outras fontes de água sob domínio privado, favorecendo condições de vida cidadã.

Seguindo a classificação de Gil (2002), a pesquisa foi do tipo exploratória/descritiva, aproximando-se, pelos procedimentos adotados, de pelo menos três outras categorias, quais sejam: bibliográfica (uma imersão na literatura nacional e estrangeira), documental (consulta a documentos, registros, arquivos dos programas destinados a solucionar/minimizar o problema de acesso à água potável) e levantamento (em banco de dados, como o do Ministério do Meio Ambiente, Secretaria de Recursos Hídricos e Ambiente Urbano, e também em campo aberto, nas comunidades beneficiadas com aplicações tecnocientíficas). 
O trabalho foi realizado em etapas interdependentes. Na primeira, buscamos conhecer e analisar o texto de criação do Programa Água Doce, tomando como fonte documentos da Secretaria de Recursos Hídricos e Ambiente Urbano, do Ministério do Meio Ambiente, (SRHU/MMA) e da Coordenação do Programa. Em seguida, realizamos levantamento da instalação das Unidades Demonstrativas (UDs) nos municípios paraibanos. Traçado esse perfil, o próximo passo foi a escolha de Unidades Demonstrativas - referências para estudo de caso. Por fim, realizamos estudo empírico, com avaliação do alcance dos objetivos, engajamento dos atores e impactos desse programa nas comunidades beneficiadas, no caso específico, a Fazenda Mata, no município de Amparo, na Paraíba.

\section{POLÍTICAS PÚBLICAS DE ÁGUA E DESENVOLVIMENTO}

Reconsiderar os modelos de desenvolvimento até aqui adotados não é apenas uma questão de modismo, mas uma necessidade urgente para proteger os ecossistemas e, consequentemente, garantir a sobrevivência da espécie humana. Um dos fatores preponderantes para a garantia da sobrevivência humana é a água um dos elementos mais ameaçados, devido o estilo de vida adotado pela sociedade. Se, por um lado, houve o aumento do seu uso, do desperdício e da poluição dos mananciais, do outro, não aumentaram as reservas, razão pela qual cresce a preocupação sobre o assunto no mundo todo. "A água perpassa todos os aspectos da vida humana. Ao longo da história, a gestão da água tem confrontado as pessoas e os governos com desafios técnicos e políticos de longo alcance" (PNUD, 2003).

De acordo com Sen,

Às vezes a ausência de liberdades substantivas relaciona-se diretamente com a pobreza econômica, que rouba das pessoas a liberdade de saciar a fome, de obter uma nutrição satisfatória ou remédios para doenças tratáveis, a oportunidade de vestir-se ou morar de modo apropriado, de ter acesso à agua tratada ou saneamento básico (SEN, 2000).

A escassez hídrica condena milhões de pessoas à vida de pobreza, com condições de saúde precárias e oportunidades limitadas. Esse resultado perpetua profundas desigualdades não só entre os países, mas também no interior dos mesmos. 


\section{PROGRAMA ÁGUA DOCE}

As décadas de 1990 a 2000 foram marcadas pela construção tanto de discursos voltados ao desenvolvimento regional quanto de formulação e execução de políticas públicas consideradas inovadoras, dentre as quais: as estratégias de combate à seca, as grandes políticas hídricas e os projetos de modernização econômica, destinados à região do Semiárido brasileiro. Nesse período, foram apresentadas duas propostas para solucionar o problema da escassez hídrica na zona rural do Semiárido brasileiro: as cisternas de placa, que armazenam água de chuva (Programa Um Milhão de Cisternas Rurais - 2003) e os sistemas de dessalinização via osmose inversa de águas subterrâneas salobras e salinas (Programa Água Doce, 2004). Essas diferentes alternativas serviram como fundamento de políticas públicas para atender os objetivos da ampliação da oferta de água para as populações rurais, no contexto da "convivência com o Semiárido".

Na Paraíba, desde a implantação do Programa Água Doce (de 2008 até 2011), foram diagnosticados 35 sistemas de dessalinização e recuperados 21 sistemas e implantadas três Unidades Demonstrativas nos municípios de Amparo, Aroeiras e Sumé. O custo de cada Unidade Demonstrativa girou em torno de R\$ $250.000,00$ (duzentos e cinquenta mil reais).

\subsection{O CASO AMPARO}

Na visão de Ham e Hill (1993), o propósito da análise de políticas é, utilizando ideias provenientes de uma série de disciplinas, interpretar as causas e consequências da ação do governo, em particular ao voltar sua atenção para o processo de formulação política. Com base em Hogwood e Gunn (1981), Ham e Hill (1993, p.13) elencam sete tipos de estudo da avaliação de políticas públicas, no entanto, o presente trabalho utiliza três: processo de elaboração de políticas, resultado de políticas e avaliação, por se aproximarem mais do nosso objeto de estudo.

Foi sobre Amparo que nossa análise se debruçou mais detalhadamente, por ter sido a primeira Unidade Demonstrativa (UD) implantada no Estado (2008/2009). 
A avaliação, a seguir, foi feita com base nos dados colhidos nas instituições parceiras do PAD e durante visitas feitas à Fazenda Mata, onde observamos como a comunidade está gerenciando a UD.

Amparo é um município localizado na mesorregião da Borborema, na microrregião do Cariri Ocidental, distante $314 \mathrm{~km}$ de João Pessoa, capital da Paraíba. Tem uma área de 121,983 km², população de 2.088 habitantes, o que corresponde a uma densidade demográfica de $17,12 \mathrm{hab} . / \mathrm{Km}^{2}$. O clima é tropical quente de seca acentuada e a vegetação predominante é a caatinga. O Índice de Desenvolvimento Humano Municipal (IDH-M), 2000, é de 0,603 (que é considerado um IDH de nível médio, embora esteja consideravelmente abaixo do IDH brasileiro que é de 0,800). Mas, levando em conta que em 1991 o IDH-M era de 0,493, podemos dizer que houve um aumento significativo desse índice. Faremos um parâmetro comparativo com o Índice Firjan de Desenvolvimento Municipal (IFDM) 2000 a 2009 para termos uma ideia do crescimento econômico e possível desenvolvimento da cidade. Em 2008, de acordo com dados de 2000 da FIRJAN, os resultados dos indicadores e do índice do Município de Amparo foram os seguintes:

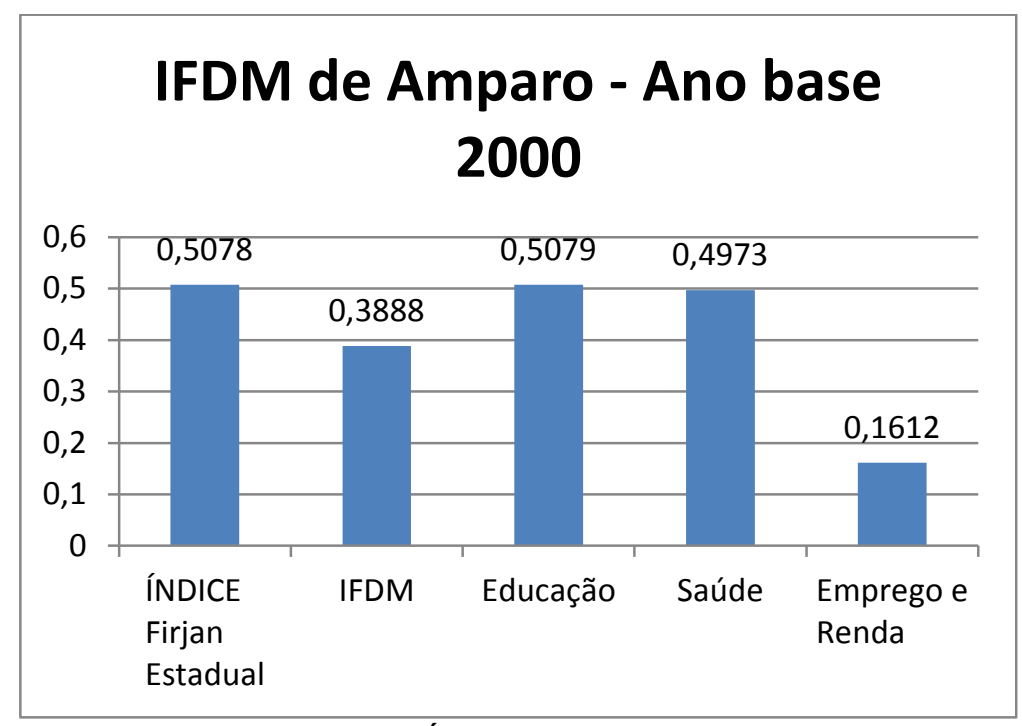

Figura 1 - Resultado do Índice e Indicadores de Amparo Fonte: IFDM, 2008

Em relação ao índice do Estado, data base 2000 edição 2008, Amparo teve baixo desenvolvimento (inferior a 0,4 pontos). No ano de 2011, os dados colhidos em 2009 se apresentaram conforme descritos na Figura 2: 


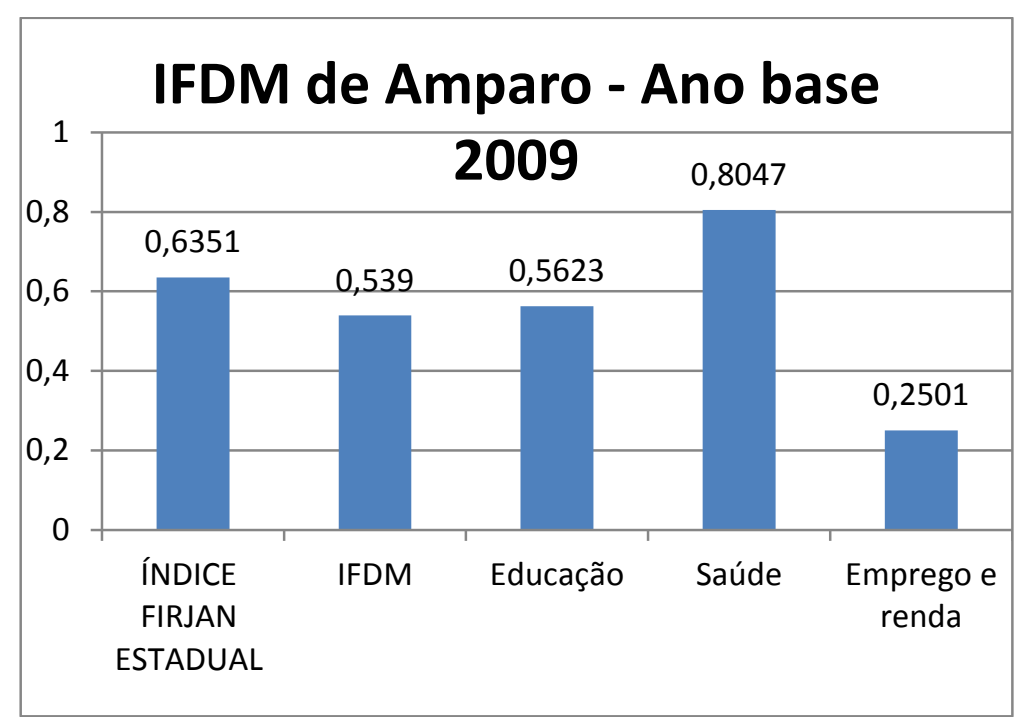

Figura 2 - Resultado do índice e indicadores de Amparo Fonte: IFDM, 2011

Comparando o índice do Estado em relação ao município (data base 2009 edição 2011), o desenvolvimento de Amparo é considerado regular entre 0,4 e 0,6 pontos. Os índices relacionados mostram a evolução anual de Amparo no período de 2000 a 2010, conforme figura 3 abaixo:

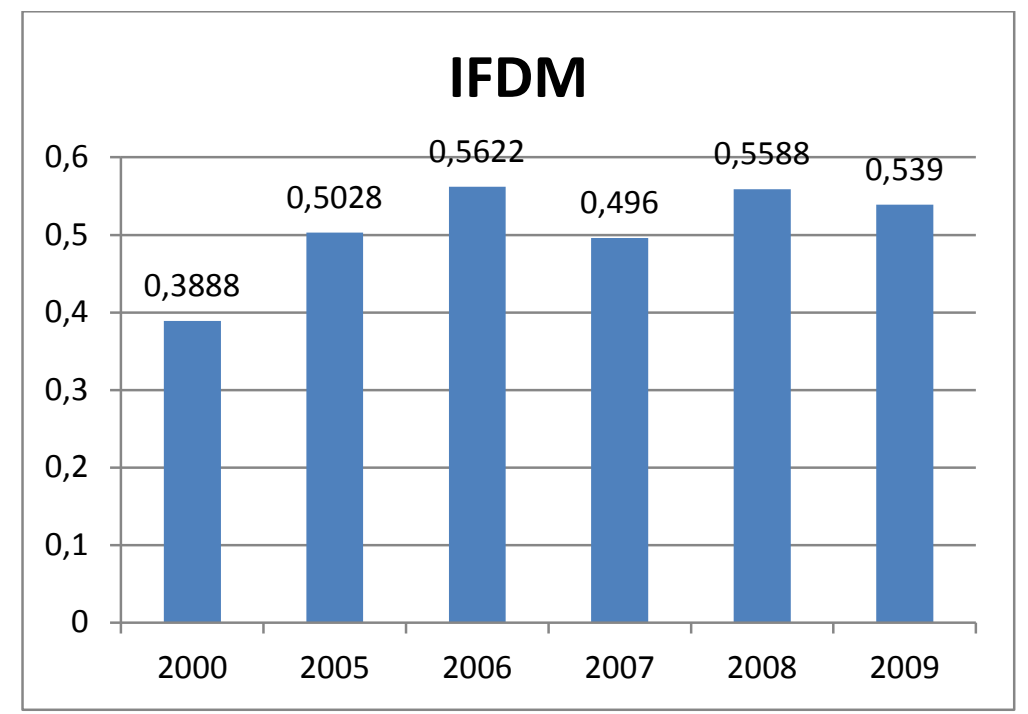

Figura 3 - Evolução anual do IFDM de Amparo no período de 2000 a 2010 Fonte: IFDM, 2011 


\subsection{CIDADE DE HÁBITOS RURAIS}

Segundo o censo do IBGE 2010, Amparo tem uma população de 2.088 habitantes, como já foi mencionado, sendo 1.026 vivendo na zona rural, isto é, quase a metade da população do Município. Empiricamente, percebem-se fortemente aspectos como hábitos, costumes e relações sociais que se aproximam mais do rural do que do urbano.

E foi na zona rural de Amparo que se instalou a primeira Unidade Demonstrativa (UD) do Programa Água Doce, na Paraíba. A UD, que teve financiamento do Banco do Brasil ${ }^{16}$, localizada no Agrupamento Fazenda Mata, 33 km distante da sede do Município, atendendo 29 famílias - num total de 85 pessoas - pertencentes à Associação dos Produtores Rurais do Sítio Caiçara, criada em 2004.

A Associação adquiriu a Fazenda da Mata que tem 574 hectares, com recursos do Programa Nacional de Crédito Fundiário (PNCF) ${ }^{17}$. A terra foi partilhada entre as famílias assentadas e cada uma ficou com 15 hectares (o que soma 435 hectares). O restante da terra, 139 hectares, foi destinado à Reserva Legal, conforme o Código Florestal através da Medida Provisória 2.166- 67 de 2001. A Unidade Demonstrativa de Amparo começou ser implantada em 2008 e foi inaugurada em 22 de outubro de 2009 e beneficia uma média de 400 pessoas que moram próximas à Unidade. As atividades que envolvem o sistema produtivo das Unidades são sempre acordadas em assembleias.

Diferentemente do que ocorre comumente na região do Semiárido, em que a água é retirada dos poços e, depois de usada, lançada no solo sem nenhum tratamento, favorecendo cada vez mais a salinização e a desertificação da região, a proposta da Unidade Demonstrativa é utilizar o concentrado produzido pelo processo de dessalinização.

No processo, representado na figura abaixo, metade da água retirada é dessalinizada e armazenada num reservatório de água potável e a outra metade se

\footnotetext{
${ }^{16}$ Foram usados também recursos do Subprojeto de Investimentos Comunitários (SIC) no valor de R\$216 mil, utilizados na construção de dois poços para o suporte do programa. O recurso também financiou a fundo perdido a compra de 58 matrizes bovinas, a construção de 21 casas e a reforma de residências.

17 A Associação comprou a Fazenda da Mata por R\$313.000,00 (trezentos e treze mil reais). A parcela anual para cada associado gira em torno de $\mathrm{R} \$ 635,00$ (seiscentos e trinta e cinco reais).
} 
torna um concentrado salinizado que é enviado a tanques de criação de tilápia peixe que se adapta com facilidade tanto à água doce como à água salgada. Periodicamente a água desses tanques é trocada e esse rejeito, em vez de ser lançado no solo, é enriquecido de matéria orgânica e aproveitado na criação de peixes e no plantio da erva-sal que é utilizado no plantio da Atriplex (erva-sal) que é usada na engorda de caprinos, ovinos e bovinos da região.

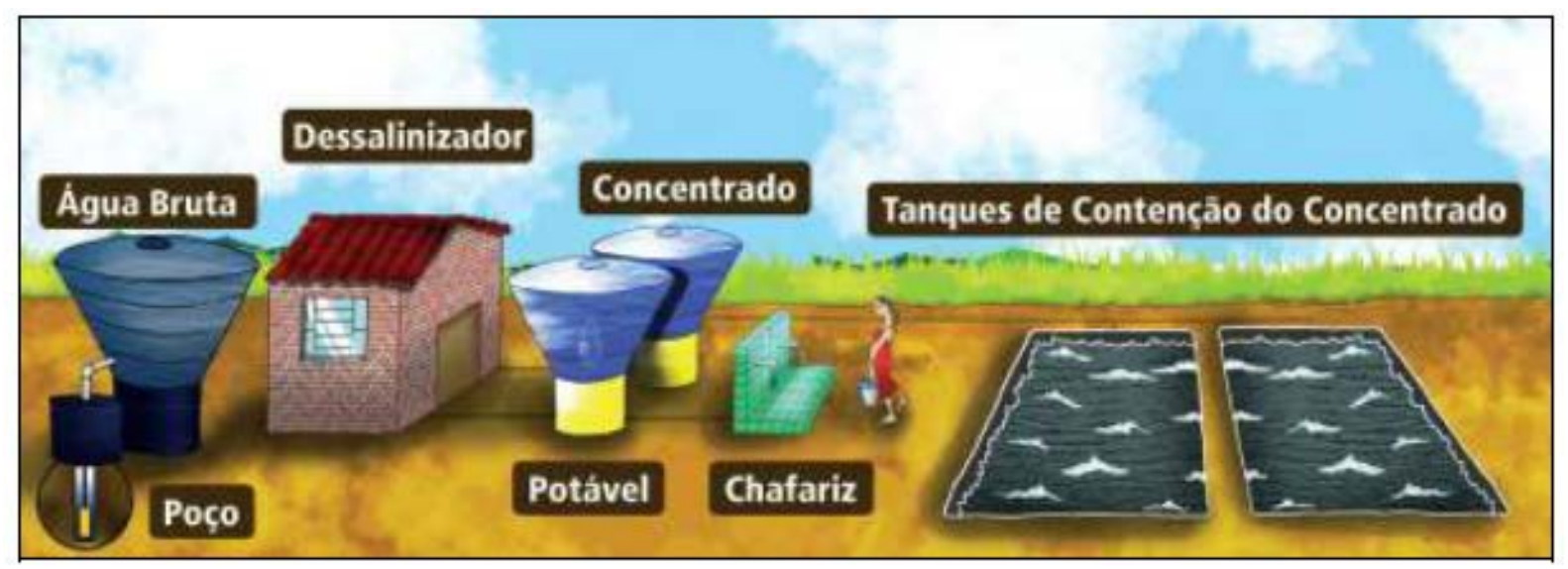

Figura 4 - Sistema de dessalinização adotado pelo PAD Fonte: MI, 2010, p. 35

Os sistemas de dessalinização utilizados pelas famílias beneficiados com o PAD são compostos principalmente, como mostra a figura 1, por uma fonte hídrica (poço tubular, bomba do poço e adução); reservatório para água bruta (chamado de reservatório de alimentação); abrigo para o dessalinizador (com uma área de 15m²); equipamento de dessalinização (que vai depender do grau de salinidade da água e, portanto, esse equipamento pode variar de região a região); reservatório para água potável e concentrado; chafariz para distribuição da água potável; reservatórios para contenção do concentrado e, ainda, cerca de proteção e portão de acesso ao sistema.

Nos Programas que antecederam o Água Doce o rejeito (ou concentrado) não tinha uma destinação objetiva; o seu descarte era feito diretamente no meio ambiente provocando um impacto ambiental negativo causando, dentre outros problemas, a esterilidade do solo

Apesar de o Programa Água Doce se colocar como uma política pública que trata da potabilidade da água através dos sistemas de dessalinização, utilizando o concentrado num sistema integrado de produção, evitando assim o impacto 
ambiental pela água potencializada de sais, Amparo - umas das cidades beneficiadas pelo PAD - não possui Conselho Municipal de Meio Ambiente e tampouco Fundo Municipal de Meio Ambiente. Além do mais, o Município não realiza licenciamento ambiental de impacto local.

\section{CONSIDERAÇÕES FINAIS}

Recorremos a Ham e Hill (1993), resgatando as três categorias de análises que foram adotadas, para compreender como se deu a construção, quais os resultados e avaliação do Programa Água Doce no Semiárido paraibano.

A pesquisa utilizou como eixos para discussão: a) o processo de elaboração de políticas; b) o seu resultado e, c) a avaliação (que chamamos de impacto) das políticas públicas de acesso à água de boa qualidade sobre a população rural do Semiárido.

O primeiro eixo, processo de elaboração da política, mostrou que a política pública de acesso à água potável para a região do Semiárido foi avaliada e modificou-se corrigindo erros detectados nos programas anteriores, a exemplo do mau uso do dessalinizador, falta de manutenção preventiva e o não envolvimento da comunidade. A remodelação do Programa Água Boa que originou o Programa Água Doce deveu-se à detecção desses e de outros defeitos. O "novo programa" foi elaborado levando em conta aspectos ambientais, sociais e econômicos trazendo como elemento inovador a Unidade Demonstrativa (UD) - que oferece não apenas água potável, mas também utiliza o concentrado, produzido pelo processo de dessalinização da água, na criação da tilápia e no cultivo da erva-sal que se torna alimento para caprinos, ovinos e bovinos.

No entanto, o PAD apresenta algumas falhas e, dentre elas, destacamos a falta de assistência técnica sistemática dos parceiros nas Unidades Produtivas; a preparação superficial dos beneficiados que operacionalizam os trabalhos dentro das Unidades (não há apropriação da tecnologia, nem um conhecimento técnico); e, ainda, a baixa produtividade da criação de tilápias, que não gera renda extra, até o momento, e a não utilização da erva-sal como complemento de ração para caprinos, ovinos e bovinos, seja pela cultura dos criadores ou por qualquer outro motivo.

As UDs - que chamamos de vitrines tecnológicas - apresentam os ajustes promovidos na concepção do PAD: aprimoramento do equipamento de 
dessalinização - montado levando em consideração aspectos técnicos e sociais como o nível de sais da água encontrada na localidade e o número de famílias a serem atendidas; a utilização do concentrado, e o envolvimento da comunidade (mesmo que ainda precário) na gestão dos recursos hídricos - que entra como mais um elemento de novidade da política de (con)vivência com o Semiárido.

O número de instituições federais, estaduais e municipais envolvidas no processo de construção do PAD chegou a vinte, o que é um fator importante e positivo. Entretanto o envolvimento da comunidade beneficiada no momento inicial da elaboração do Programa foi quase inexistente, salvo uma informação dada aqui e ali durante as visitas feitas aos locais onde se diagnosticou a situação dos poços e dos dessalinizadores, realizadas em 2003. A decisão de como construir, implantar e inovar continuou sendo unilateral.

O segundo eixo, estudos de resultados da política, desnudou as nuances do Programa Água Doce no Estado e denunciou a fragilidade do alcance dos números (os ganhos obtidos). No período 2004/2012 foram implantados e/ou recuperados, por meio do PAD, um total de 24 sistemas de dessalinização, sendo três Unidades Demonstrativas e 21 sistemas simples, atendendo cerca de 30 mil pessoas. Embora o Programa seja relevante, o seu alcance social se mostra pequeno diante da problemática da escassez de água para o consumo humano na região do Semiárido paraibano.

O terceiro eixo, a avaliação, teve como premissas a elaboração e o resultado da política pública. As transformações promovidas pelo Programa, embora importantes, alcançam apenas um reduzido número de pessoas. Na prática, verificou-se que as Unidades Demonstrativas, cujo preço gira em torno de $R \$ 250$ mil, cada uma, têm um custo elevado e, ainda, que o Sistema Integrado não se sustente por si só, não é autossustentável. Com relação à participação da comunidade, notou-se que aconteceu de maneira tímida e que as decisões direcionadas ou tomadas pelas instituições financiadoras nas várias esferas (federal, estadual e municipal) tiveram um peso maior na construção desse processo. 


\section{REFERÊNCIAS}

Banco do Nordeste do Brasil. FNE 2011 - Fundo Constitucional de Financiamento do Nordeste - programação regional / Banco do Nordeste do Brasil. - Fortaleza, 2011, 105p. Disponível em:

<http://www.bnb.gov.br/content/aplicacao/sobre_nordeste/fne/docs/programacao_fne _2011_reprogramada.pdf>. Acesso em: 08 set. 2010.

BLANK, Dionis Mauri Penning; HOMRICH, Ivone da Graça Nunes; ASSIS, Simone Vieira. de. $\mathrm{O}$ gerenciamento dos recursos hídricos à luz do ecodesenvolvimento. Revista Eletrônica do Mestrado em Educação AmbientalFURG-RS. v. 20, p.53, jan/jun. de 2008.

BRASIL, Ministério do Desenvolvimento Social. Semiárido. Brasília. 2010.

Disponível em: <www.mds.org.br>. Acesso em: 10 ago. 2010.

. Ministério da Integração Nacional. Nova delimitação do Semiárido

brasileiro - cartilha. Disponível em:

<http://www.museusemiarido.org.br/expedicao/cartilha_delimitacao_semi_arido.pdf>. Acesso em: 22 set. 2010.

Ministério do Meio Ambiente. Disponível em:<

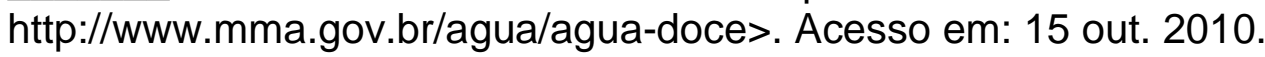

GIL, A.C. Como elaborar projetos de pesquisa. 4 ed. São Paulo: Atlas, 2002.

HAM, Cristopher e HILL, Michael. O processo de elaboração de políticas no estado capitalista moderno. (tradução para o português de The policy process in the modern capitalist state). Londres, 1993, sob a responsabilidade de Renato Amorim e Renato Dagnino para uso exclusivo nos Programas de Capacitação do GAPI-UNICAMP e nas disciplinas ministradas pelo DPCT-UNICAMP.

ORGANIZAÇÃO MUNDIAL DE SAÚDE (OMS). Água e Saúde. Publicado em 2001. Disponível em: <http://www.opas.org.br/sistema/fotos/agua.PDF> Acesso em 14 maio 2012.

PNUD. Atlas do desenvolvimento humano no Brasil. Disponível em: <www.pnud.org.br>.

Acesso em: 03 nov. 2003.

SISTEMA FIRJAN. Índice Firjan de Desenvolvimento Municipal - IFDM-

Disponível em:

<http://www.firjan.org.br/data/pages/40288094212F79010121314832D46D33.htm>. Acesso em 23 maio 2012.

SEN, A. Desenvolvimento como liberdade. São Paulo: Companhia das Letras, 2000. 